\title{
Erratum
}

\section{Erratum: Shibata et al., Projection Patterns of Corticofugal Neurons Associated with Vibrissa Movement}

In the article "Projection Patterns of Corticofugal Neurons Associated with Vibrissa Movement," by Ken-Ichi Shibata, Takuma Tanaka, Hiroyuki Hioki, and Takahiro Furuta, which published online on October 4, 2018, the authors noted the following errors:

Table 2 (reprinted below) incorrectly indicates that neuron 148 and neuron 089 sent axons to the PN structure. These two neurons did not send axons to the structure.

In the legend for Figure 3, "LA whisking" at two places should be clarified to read as "large-amplitude whisking."

https://doi.org/10.1523/ENEURO.0346-19.2019

Table 2. Summary of the distribution of labeled axon fibers contralateral to the cell body

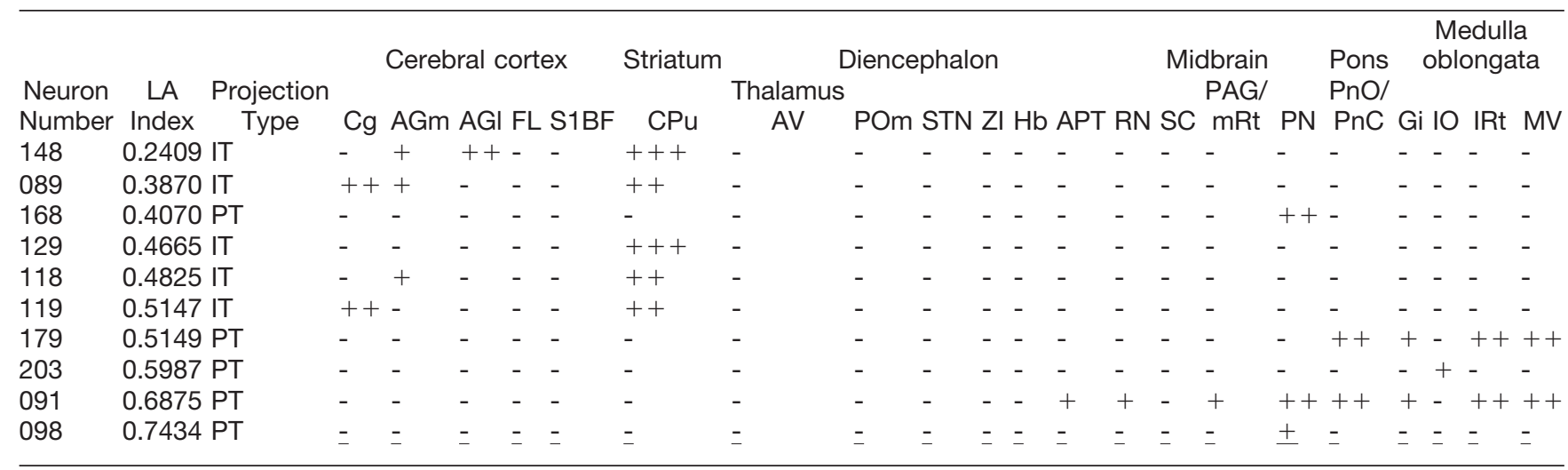

